\title{
Correction to: Mixture deconvolution by massively parallel sequencing of microhaplotypes
}

\author{
Lindsay Bennett ${ }^{1} \cdot$ Fabio Oldoni ${ }^{2} \cdot$ Kelly Long $^{2} \cdot$ Selena Cisana $^{2} \cdot$ Katrina Maddela $^{2} \cdot$ Sharon Wootton $^{3} \cdot$ \\ Joseph Chang ${ }^{3} \cdot$ Ryo Hasegawa $^{3} \cdot$ Robert Lagacé $^{3} \cdot$ Kenneth K. Kidd ${ }^{4} \cdot$ Daniele Podini $^{2}$
}

Published online: 5 March 2019

(C) Springer-Verlag GmbH Germany, part of Springer Nature 2019

Correction to: International Journal of Legal Medicine 2019 https://doi.org/10.1007/s00414-019-02010-7

The original version of this article contained an author name error. In this article, Katrina Madella has been corrected to Katrina Maddela.

Publisher's note Springer Nature remains neutral with regard to jurisdictional claims in published maps and institutional affiliations.

The online version of the original article can be found at https://doi.org/ 10.1007/s00414-019-02010-7

Daniele Podini

podini@gwu.edu

1 Metro Nashville Police Department Crime Laboratory, 400 Myatt Drive, Madison, TN 37115, USA

2 The Department of Forensic Sciences, The George Washington University, 2100 Foxhall Road NW, Washington, D.C. 20007, USA

3 Thermo Fisher Scientific, 180 Oyster Point Boulevard, San Francisco, CA 94080, USA

4 Department of Genetics, Yale University, 333 Cedar Street, New Haven, CT 06520, USA 